\title{
PRELIMINARY EVALUATION OF SEISMIC PERFORMANCE OF ENGINEERING STRUCTURES WITH PERFORM 3D
}

\begin{abstract}
DONGMEI LI ${ }^{1}$
This study analyzed the role of PERFORM 3D in the preliminary evaluation of seismic performance of engineering structures. Firstly, PERFORM 3D was briefly introduced, and its material constitutive model and basic model were analyzed. Then, taking a high-rise building project in Yulin, Shaanxi, China, as an example, PERFORM 3D was used to evaluate its seismic performance. After establishing the engineering model, five seismic waves were selected for simulation. The results showed that the maximum values of $\mathrm{X}$-axis inter-story displacement angle and Y-axis displacement angle were 1/500 and 1/360 respectively, which were far less than the standard limit; the overall energy dissipation was good, the damping was small, the overall deformation was good, and the seismic performance was also good. In conclusion, PERFORM 3D has a good performance in the preliminary evaluation of seismic performance of engineering, and it is worth further promotion and application. Key word: PERFORM 3D, elastoplastic analysis, seismic performance, inter-story displacement angle
\end{abstract}

\section{INTRODUCTION}

Earthquake is a natural disaster with serious consequences. Despite the continuous development of science and technology, the understanding of earthquakes is still very limited and it is difficult to predict earthquakes effectively. Therefore, the seismic performance analysis of buildings is very important [1]. In order to ensure certain seismic performance, a seismic performance-based design theory [2] emerges, that is, making the design of the project meet the seismic performance

\footnotetext{
${ }^{1}$ School of Architecture and Engineering, Yulin University, Yulin, Shannxi 719000, China Corresponding address: No. 51, Chongwen Road, Yulin, Shaanxi 719000, China ORCID: 0000-0002-6610-8562, Email: dmli_dmei@yeah.net
} 
objectives within the service life through seismic performance analysis, and the engineering performance can be evaluated through indicators such as displacement, acceleration and force [3].

Su et al. [4] studied the structural integrity and structural bearing capacity of buildings, took the damage degree of buildings as the criterion for evaluating the seismic performance of buildings, and proved the feasibility of this evaluation method through experiments. Hossein et al. [5] evaluated the anti-seismic performance of air traffic control tower by pushover analysis and found that the tower was subjected to low lateral stiffness at a high level and the stress value of outer wall concrete was smaller than the design value. Xu et al. [6] analyzed the seismic performance of composite ultra-high performance concrete steel frames using ABAQUS. It was found that the deformation and shear stress of the structure were significantly reduced compared with traditional frames and the energy dissipation performance and damage control were effectively improved. Liu et al. [7] evaluated the seismic performance of a power plant and found that the plant had good integrated stiffness and its inter-story displacement angle met the requirements of seismic deformation. In order to better evaluate the seismic performance of project, PERFORM 3D software was studied in this paper. Taking a project in Yulin, Shanxi, China, as an example, an engineering model was established, and five seismic waves were simulated to analyze its seismic performance. The experimental results proved the effectiveness of PERFORM 3D software in seismic performance evaluation. The study can provide a reference for engineering design.

\section{PERFORM 3D SOFTWARE}

PERFORM 3D is a non-linear software for studying seismic performance [8], which can be used for dynamic and static analysis at the same time. Compared to other software of the same kind, PERFORM 3D has strong non-linear analysis ability, and it adopts graphical interactive input interface, which is more operable than text input. PERFORM 3D supports the analysis of many elements, such as frames, shear walls, beams, columns, floors, etc., and outputs results such as use ratio, Pushover [9] and deformation shape. It has a wide applications in the study of seismic performance.PERFORM 3D software directly uses the way of picture input, which is easy to operate and has low error rate. Its general analysis process (Pushover analysis as an example) is shown in Fig. 1. 


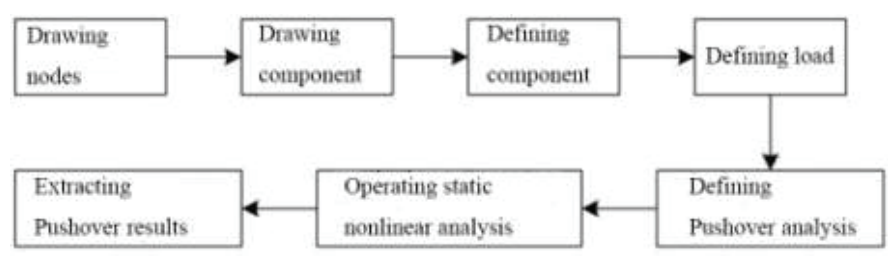

Fig. 1. Analysis process of PERFORM 3D

\subsection{BASIC MODEL}

\subsubsection{BEAM-COLUMN ELEMENT MODEL}

The beam-column element model includes the following three types:

(1) Plastic hinge model (Fig. 2). The plastic and elastic deformations of beams and columns are simulated by plastic hinges and elastic segments.

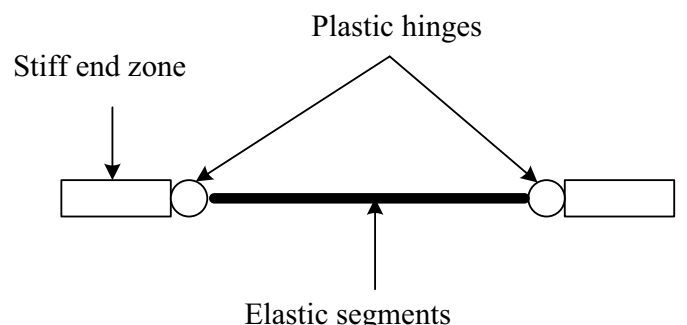

Fig. 2. Plastic hinge model

(2) Plastic zone model (Fig. 3). The two ends of beam and column are plastic zones, and the middle is the elastic segment. The length of the plastic zone can be calculated by the following formula: $L_{p}=0.08 L+0.022 d f_{y}(M P a)$, where $L_{p}$ represents the length of the plastic zone, $L$ represents the distance from the reverse bending point to the maximum bending moment, $d$ represents the diameter of longitudinal steel bars, and $f_{y}$ represents the yield strength of longitudinal steel bars. 


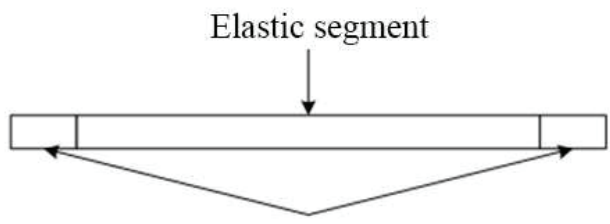

Plastic zone

Fig. 3. Plastic zone model

(3) Finite element model (Fig. 4). Beams and columns are divided into several elastic-plastic elements, which require a large amount of calculation.

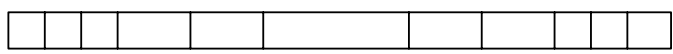

Fig. 4. Finite element model

\subsubsection{WALL ELEMENT MODEL}

The wall in PERFORM 3D is simulated by fiber model, including shear wall element and general wall element.

Shear wall element can be used to simulate the response of wall limbs with large height-span ratio. The bending and shear deformation can be separated first and then superimposed. General wall unit can simulate the two-way bending and shearing in the plane, as well as the diagonal baroclinic bar effect.

\subsection{MATERIAL CONSTITUTION}

\subsubsection{CONSTITUTIVE CONSTITUTION OF CONCRETE}

In this paper, the improved Mander model [10] was used for simulating confined concrete (Fig. 5), which can be expressed as follows.

When $0 \leq \varepsilon_{c} \leq \varepsilon_{c u}, \sigma_{c}=\frac{f_{c c} x r}{r-1+x^{r}}$; when $\varepsilon_{c} \geq \varepsilon_{c u}, \sigma_{c}=0$.

$$
x=\frac{\varepsilon_{c}}{\varepsilon_{c c}} \text { and } r=\frac{E_{c}}{E_{c}-E_{\mathrm{sec}}},
$$

where: 
$\varepsilon_{c}-$ strain, $\varepsilon_{c u}-$ the ultimate compressive strain, $\sigma_{c}-$ stress, $f_{c c}-$ peak stress, $\varepsilon_{c c}-$ strain when the compressive strength is $f_{c c}, E_{c}$ - the modulus of elasticity of concrete, and $E_{\text {sec }}-$ the secant slop. Moreover, $\varepsilon_{c u}=0.004+1.4 \rho f_{y h} \frac{\varepsilon_{s u}}{f_{c c}}$, where $\rho$ represents volume stirrup ratio, $f_{y h}$ represents the yield strength of stirrups, and $\varepsilon_{s u}$ represents the ultimate tensile strain of stirrups;

$$
\begin{gathered}
f_{c c}=k_{f c} \\
k=2.254 \sqrt{1+3.97 k_{e} \lambda}-k_{e} \lambda-1.254
\end{gathered}
$$

where:

$k$ - the strength enhancement factor of concrete, $k_{e}-$ the effective constraint coefficient of the cross section, 0.75 here, and $\lambda-\mathrm{s}$ the stirrup eigenvalue;

$$
E_{\mathrm{sec}}=\frac{f_{c c}}{\varepsilon_{c c}}
$$

where:

$$
E_{c}=5000 \sqrt{f_{c}}
$$

$f_{c}$ - the strength of unconstrained concrete.

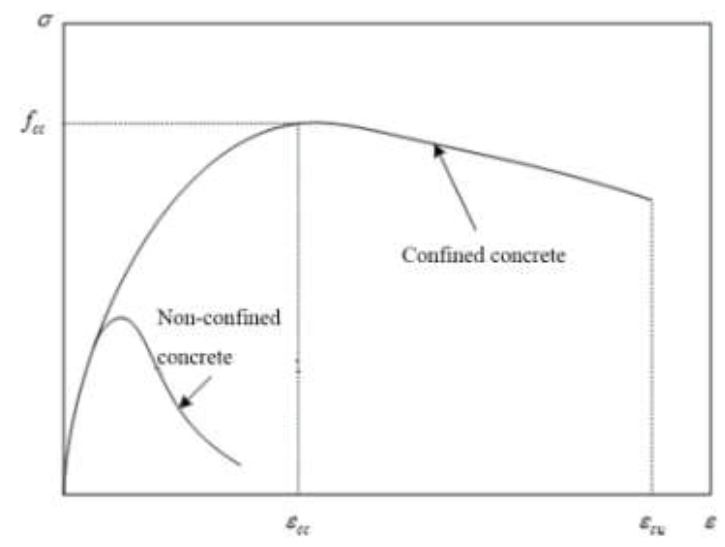

Fig. 5. Confined concrete model 


\subsubsection{REINFORCEMENT CONSTITUTION}

Giuffré-Menegotto-Pinto model (Fig. 6) is used for constitutive analysis of reinforcing bars. The stress-strain relationship can be expressed as follows:

$$
\sigma=b \varepsilon+\frac{(1-b) \varepsilon}{\left(1+\varepsilon^{R}\right)^{1 / R}}
$$

$$
\varepsilon=\frac{\varepsilon-\varepsilon_{r}}{\varepsilon_{0}-\varepsilon_{r}}
$$

$$
b=\frac{E_{1}}{E_{0}}
$$

where: $\sigma$ - stress, $\varepsilon-$ strain, $\varepsilon_{0}-$ the strain at the yield point of the bilinear envelope, $\varepsilon_{r}-$ the reverse point strain, and $b$ - the ratio of stiffness of rebar $E_{1}$ to tangent modulus $E_{0}$.

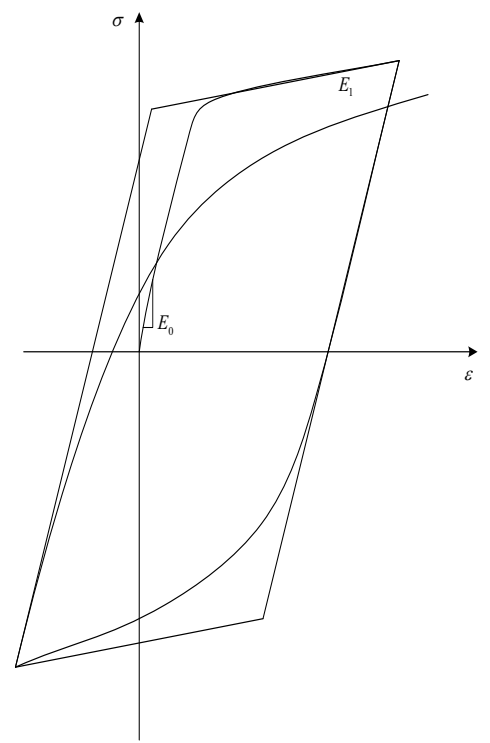

Fig. 6. Reinforcing bar model 


\section{SEISMIC PERFORMANCE ANALYSIS WITH PERFORM 3D}

\subsection{Project OVERVIEW}

An engineering project in Yulin, Shaanxi, China, (Fig. 7) was taken as an example, and its earthquake intensity was 6 degrees $(0.05 \mathrm{~g})$, belonging to the first group of earthquake. The project was a standard office building with 50 floors above ground. The total height of of the building was $228 \mathrm{~m}$ and the height of the standard floor was $4.2 \mathrm{~m}$. It is a frame-reinforced concrete core tube system.

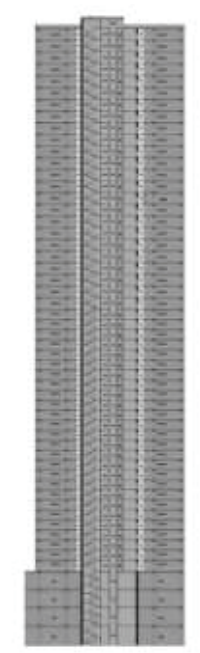

Fig. 7. Engineering design drawing

\subsection{ANALYSIS MODEL}

In order to reduce the complexity of modeling, the preliminary engineering modeling was carried out in ETABS, txt file was exported, the model was imported into PERFORM 3D, and the information such as injected material attributes was added to the model to complete the modeling. The construction in PERFORM 3D all used fiber models. The principle of fiber model is: the cross section of the component is divided into plane grid, the center of the grid is the numerical integral point, and the longitudinal microsegment. The beam-column element model adopted plastic zone model. The wall element model adopted shear wall element. $5 \%$ of modal damping was exerted on 
the structural period segment, and moreover $0.1 \%$ of Rayleigh damping was superimposed to eliminate high-frequency vibration.

\subsection{MATERIAL STRENGTH}

The average values of the strength of all materials were selected as the material intensity, and its calculation formula is:

$$
f_{a}=\frac{f_{k}}{1-1.645 \sigma}
$$

where:

$f_{a}$ - the average strength, $f_{k}$ - the standard value of strength, and $\sigma$ - coefficient of variation.

The materials used in the project, coefficient of variation and the calculated average strength value are shown in Table 1.

Table 1. Material, coefficient of variation and average strength

\begin{tabular}{|c|c|c|}
\hline Material & $\begin{array}{c}\text { Coefficient of variation } \\
(\%)\end{array}$ & $\begin{array}{c}\text { Average strength } \\
\text { (MPa) }\end{array}$ \\
\hline C30 & 17.1 & 33.05 \\
\hline C40 & 15.6 & 42.5 \\
\hline C50 & 14.9 & 52.3 \\
\hline C60 & 14.1 & 61.7 \\
\hline HRB335 & 7.43 & 381.6 \\
\hline
\end{tabular}

\subsection{SEISMIC WAVE}

In the analysis of seismic performance, the choice of seismic wave will have an impact on the analysis results. Under different seismic waves, output such as internal force and displacement of the structure will vary. Five seismic waves were selected from PEER Ground Motion Databases of the Pacific seismic center, as shown in Table 2.

Table 2. Information of seismic wave

\begin{tabular}{|c|c|c|c|c|}
\hline Number & Event & Time & Seismic station & Magnitude \\
\hline A & Chi-Chi-Taiwan & 1999 & TTN051 & 7.62 \\
\hline B & Kocaeli-Turkey & 1999 & Istanbul & 7.51 \\
\hline C & Loma Prieta & 1989 & Agnews State Hospital & 6.93 \\
\hline D & San Fernando & 1971 & 2516 Via Tejon PV & 6.61 \\
\hline E & Imperial Valley-06 & 1979 & Westmorland Fire Sta & 6.53 \\
\hline
\end{tabular}




\subsection{EVALUATION INDEX}

The seismic performance of the project was evaluated by the inter-story displacement angle and the overall energy dissipation. Inter-story displacement angle refers to the ratio of maximum horizontal displacement between floors to floor height, which can be used to evaluate the stiffness of engineering structures. The overall energy dissipation includes kinetic energy, strain energy, damping energy and hysteretic energy. After absorbing seismic energy, a small part of the engineering structure is transformed into kinetic energy and strain energy, most of which are damped energy and hysteretic energy. Hysteretic energy dissipation can show the plastic damage of structures by earthquake.

\section{SEISMIC PERFORMANCE EVALUATION}

\subsection{INTER-STORY DISPLACEMENT ANGLE}

After processing by PERFORM software, the extracted inter-story displacement angle of the project is shown in Fig. 8 and 9.

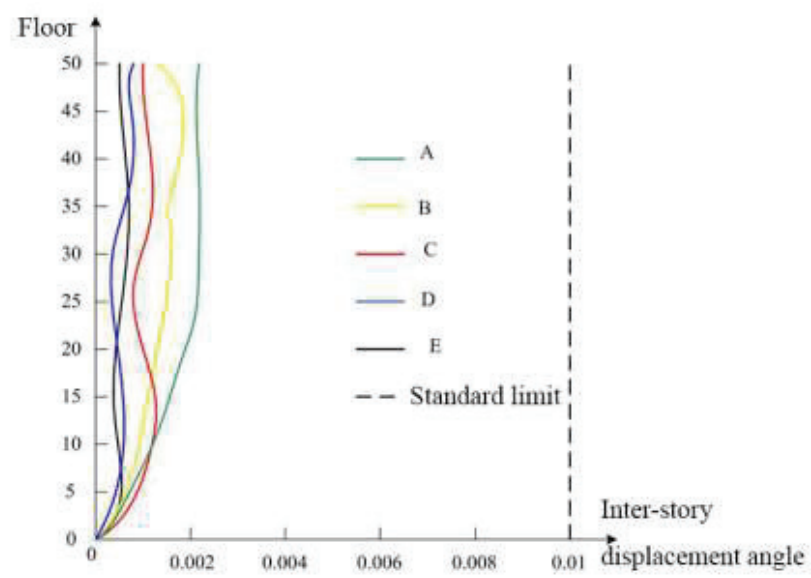

Fig. 8. Inter-story displacement angle in the direction of $\mathrm{X}$ axis 


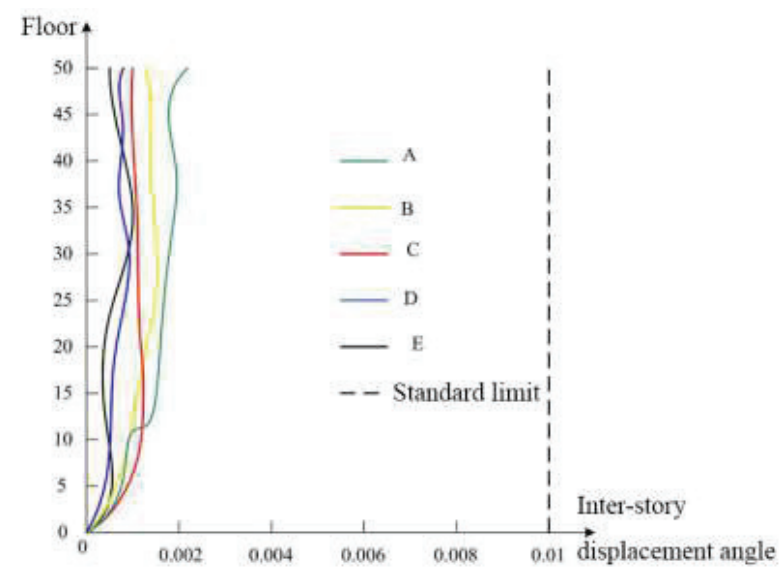

Fig. 9. Inter-story displacement angle in the direction of $\mathrm{Y}$ axis

According to Code for Seismic Design of Building (GB50011-2010) [11], under earthquake action, the standard limit value of the inter-story displacement angle was 1/100. It was found from Fig. 2 and 3 that the inter-story displacement angle of the project was far less than $1 / 100$, in which the inter-story displacement angle of seismic wave A and B was large, and the maximum value is shown in Table 3.

Table 3. The maximum inter-story displacement angle

\begin{tabular}{|c|c|c|}
\hline Seismic wave & Direction of $X$ axis & Direction of Y axis \\
\hline A & $1 / 500$ & $1 / 362$ \\
\hline B & $1 / 652$ & $1 / 875$ \\
\hline C & $1 / 1142$ & $1 / 1265$ \\
\hline D & $1 / 1332$ & $1 / 1485$ \\
\hline E & $1 / 1825$ & $1 / 1696$ \\
\hline
\end{tabular}

It was found from Table 3 that the maximum value of inter-story displacement angle in the direction of $\mathrm{X}$ axis was $1 / 500$ and the minimum value was $1 / 1825$; the maximum value in the direction of $\mathrm{Y}$ axis was $1 / 362$ and the minimum value was $1 / 1696$, which were all smaller than the standard limit value. It indicated that the project had good lateral stiffness and deformation performance.

\subsection{OVERALL ENERGY DISSIPATION}

It was found from Fig. 10 and 11 that the engineering structure had strong response under seismic wave A and B. Therefore, the overall energy dissipation of the structure was analyzed taking A and B as examples. 
The influence of seismic wave on structure is a process of energy transmission, transformation and consumption. Seismic energy is stored partly in the form of kinetic energy and strain energy and partly dissipated. If the total energy consumption of structure is balanced with the input energy of earthquake, the structure will not collapse in the earthquake. Under seismic waves A and B, the energy dissipation of the structure is shown in Fig. 10 and 11.

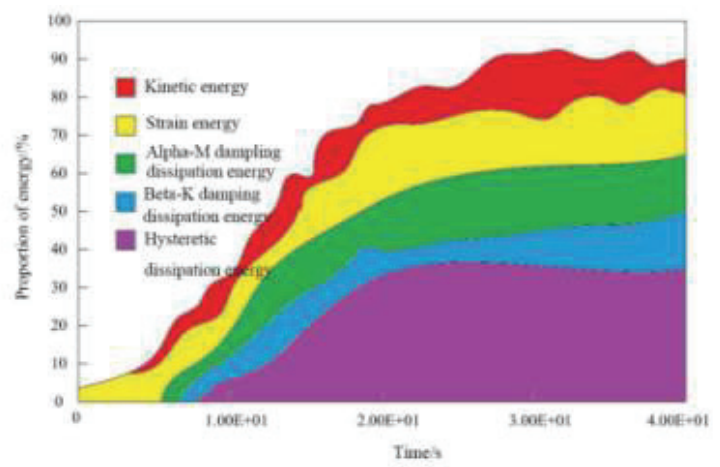

Fig. 10. The overall energy dissipation under seismic wave A

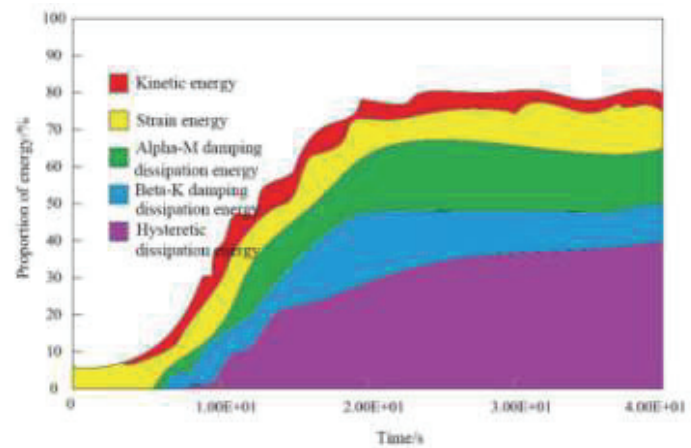

Fig. 11. The overall energy dissipation under seismic wave B

On the whole, nearly half of the engineering structures was in non-linear state under earthquake action. It was found from Fig. 10 and 11 that the hysteretic energy consumption under seismic wave A was relatively large, about $54 \%$, and that under seismic wave B was relatively small, about $42 \%$. After input of seismic wave, strain energy was the first energy consumed, followed by kinetic energy, damping energy and hysteretic energy. Among all the energies, hysteretic energy accounted for the largest proportion, about $50 \%$, followed by damping, which showed that the magnitude of damping had a great impact on the overall performance of the structure; the smaller the damping, the better the performance of the structure. 


\section{DISCUSSION}

It is of great significance to evaluate the seismic performance of buildings [12]. The traditional seismic design method mainly guarantees that a building will not collapse in a great earthquake [13] According to the current seismic situation, the traditional seismic design method can make the building not collapse in a great earthquake, but it can not avoid the destruction of the building and is difficult to guarantee the practicability of the building. Therefore, the seismic design method for evaluating the performance of buildings emerges to make up for the shortcomings of the traditional methods [14]. In the performance evaluation, the seismic performance of a building can be evaluated by simulating the earthquake action that the building may suffer and giving the indicators of buildings such as displacement and damage to grasp the structural performance of a building more comprehensively and reduce and mitigate the seismic consequences to the greatest extent [15]. Firstly, the operation of PERFORM 3D was simply analyzed, and then the material constitutive relationship and the basic model of PERFORM 3D were mainly introduced. In PERFPRM 3D, there are many construction types, such as beams, columns, slabs, shear walls and so on, which can simulate buildings well; hence it has been widely used. In the case analysis, this study took a highrise building project in Yulin, Shaanxi, China as an example. Firstly, the engineering modeling was carried out, the basic modeling was performed through ETABS and imported into PERFORM 3D, and the basic information of materials was input to complete the overall modeling. In the selection of seismic waves, five seismic waves are selected from PGMD for simulation according to the actual situation of the project.

From the perspective of the inter-story displacement angle, the standard limit value of the project was 1/100. It was found from Fig. 2 and 3 that the inter-story displacement angles of $X$ axis and $Y$ axis were significantly smaller than the standard limit value under the action of seismic waves selected, the inter-story displacement angles under seismic waves A and B were relatively large, the maximum value of the inter-story displacement angle in the direction of $X$ axis was $1 / 500$, the maximum value in the direction of $\mathrm{Y}$ axis was $1 / 362$, and the standard limit value was $1 / 100$. It indicated that the inter-story displacement angle of the project met the requirements and had good lateral stiffness. From the perspective of the overall energy consumption, the proportion of hysteretic and damped energy dissipation was large after the elastic-plastic state of the engineering structure, which showed that damping had a great impact on the overall performance of the structure. On the whole, the project had good seismic performance. 


\section{CONCLUSION}

In this paper, the role of PERFORM 3D software in seismic performance evaluation was simply studied. Taking a project as an example, the analysis of inter-story displacement angle and overall energy dissipation showed that the inter-story displacement angle of the project was less than the standard limit under the action of different seismic waves, the overall deformation met the requirements, and the overall seismic performance was good, which suggested the role of PERFORM 3D software in the preliminary evaluation of engineering seismic performance. This study makes a contribution to the performance evaluation of engineering.

\section{REFERENCES}

1. R. Han, Y. Li, V. D. L.John, "Impact of aftershocks and uncertainties on the seismic evaluation of non-ductile reinforced concrete frame buildings", Engineering Structures 100: 149-163, 2015.

2. Ö. Ali Ruzi, "Performance-based Seismic Design of an Irregular Tall Building-A Case Study", Structures 5: 112-122, 2016.

3. C. P. Pantelides, C. Clyde, L. D. Reaveley, "Performance-Based Evaluation of Reinforced Concrete Building Exterior Joints for Seismic Exchange”, Earthquake Spectra 18(3): 449-480, 2002.

4. Q. W. Su, S. C. Zhao, L. P. Ye, "Research on seismic evaluation of masonry structures", Journal of Building Structures 35(1): 111-116, 2014.

5. M. Hossein, V. Mohammadreza, "Seismic Performance Evaluation of an ATC Tower through Pushover Analysis", Structural Engineering International 1-6, 2018.

6. T. F. Xu, D. Zheng, C. Yang, K. L. Deng, "Seismic performance evaluation of damage tolerant steel frame with composite steel-UHPC joint”, Journal of Constructional Steel Research 148: 457-468, 2018.

7. H. Q. Liu, W. B. Liu, R.Y. Wu, "The Elastic-Plastic Time History Analysis on High-Rise Steel Structure about Main Power House of Thermal Power Plant”, Applied Mechanics and Materials 578-579: 214-219, 2014.

8. H. Jiang, S. Li, Y. Zhu, "Seismic performance of high-rise buildings with energy-dissipation outriggers", Journal of Constructional Steel Research, 134: 80-91, 2017.

9. Lpez-Lpez, A. Toms, G. Sánchez-Olivares, "Influence of adjusted models of plastic hinges in nonlinear behaviour of reinforced concrete buildings", Engineering Structures 124: 245-257, 2016.

10. T. H. Han, J. M. Stallings, Y. J. Kang, "Nonlinear concrete model for double-skinned composite tubular columns", Construction \& Building Materials 24(12): 2542-2553, 2010.

11. Former Ministry of Urban and Rural Building and Environmental Protection of China. Code for Seismic Design of Building. China Building Industry Press, 1991.

12. L. Halder, S. Paul, "Seismic Damage Evaluation of Gravity Load Designed Low Rise RC Building Using Nonlinear Static Method”, Procedia Engineering 144: 1373-1380, 2016.

13. L. N. Pei, "Performance-Based Research of Existing Reinforced Concrete Building Structure Seismic Evaluation and Reinforcement Technology", Applied Mechanics and Materials 513-517: 3500-3503, 2014.

14. M. Zameeruddin, K. Sangle, "Review on Recent developments in the performance-based seismic design of reinforced concrete structures", Structures 6: 119-133, 2016.

15. R. Catulo, A. P. Falcao, R. Bento, S. Ildefonso, "Simplified evaluation of seismic vulnerability of Lisbon Heritage City Centre based on a 3D GIS-based methodology”, Journal of Cultural Heritage 32: S1296207417301073, 2018.

\section{LIST OF FIGURES AND TABLES:}

Fig. 1. Analysis process of PERFORM 3D

Fig. 2. Inter-story displacement angle in the direction of $\mathrm{X}$ axis

Fig. 3. Inter-story displacement angle in the direction of $Y$ axis

Fig. 4. The overall energy dissipation under seismic wave A

Fig. 5. The overall energy dissipation under seismic wave B

Tab. 1. Material, coefficient of variation and average strength

Tab. 2. Information of seismic wave 